\title{
PENGETAHUAN REMAJA MENGENAI KESEHATAN REPRODUKSI DI SMA NEGERI JATINANGOR
}

\author{
Winie Sintya Putri'), Neneng Martini'2), Merry Wijaya ${ }^{3)}$, Sri Astuti4), Lani Gumilang ${ }^{5)}$ \\ ${ }^{1}$ Program Pendidikan DIV Kebidanan Fakultas Kedokteran Universitas Padjajaran \\ Email: Winiesintya12@yahoo.com \\ ${ }^{2}$ Departemen IImu Kesehatan Masyarakat Fakultas Kedokteran Universitas Padjajaran \\ Email: Neneng_martini@yahoo.co.id \\ ${ }^{3}$ Departemen Ilmu Kesehatan Masyarakat Fakultas Kedokteran Universitas Padjajaran \\ Email: Merry_wijaya0605@yahoo.com \\ ${ }^{4}$ Departemen IImu Kesehatan Masyarakat Fakultas Kedokteran Universitas Padjajaran \\ Email: Sriastuti29@gmail.com \\ ${ }^{5}$ Departemen IImu Kesehatan Masyarakat Fakultas Kedokteran Universitas Padjajaran \\ Email: Lanigumilang88@gmail.com
}

\begin{abstract}
Introduction: Youth is a transition period from childhood to a more mature person, starting from physical and psychological changes. To date, teenagers cannot be separated from reproductive health problems. Due to the proliferation of reproductive health cases among adolescents, BKKBN established Youth Reproductive Health Information and Counseling Center program with the aim of increasing adolescent awareness of both male and female reproductive health. The purpose of this study was to identify adolescent's knowledge about reproductive health in Jatinangor Senior High School.

Methods: Method used in this study was descriptive, and sampling technique used was stratified and purposive sampling with a sample size of 88 students in Jatinangor Senior High School, and the data was analyzed using frequency distribution to measure adolescent's knowledge.

Results: The number of respondents who took part in the study was equally numerous, with the majority of late teenage respondents aged 16-19 years as many as 58 respondents (65.9\%). The last education of the respondents' fathers was mostly SMA/K as many as 25 respondents $(28.4 \%)$, while for the last education the mothers of high school / SMK respondents were 39 respondents (44.3\%). The work of the majority respondent's father as an entrepreneur 31 respondents (35.2\%) Whereas, the majority of the work of the mother is Not working I IRT 61 respondents (69.3\%). All respondents (100\%) did not participate in the PIK-KRR Program, the majority of them received information sources through their peers as many as 35 respondents (39.7\%). At the level of knowledge the results of the knowledge level of the majority of male students with sufficient knowledge were 31 respondents (68.9\%) while the majority of female students were sufficiently knowledgeable as many as 23 (52.3\%) respondents.

Conclusion: The level of knowledge of adolescents in Jatinangor Senior High School regarding reproductive health is the majority of students who are knowledgeable enough.
\end{abstract}

Keywords: Knowledge, Youth, Reproductive Health

\section{ABSTRAK}

Pendahuluan: Remaja adalah suatu masa transisi dari masa anak-anak menjadi pribadi yang lebih dewasa, dimulai dari perubahan fisik, dan psikologis. Dan saat ini remaja tidak bisa terlepas dari masalah kesehatan reproduksi. Dengan maraknya kasus kesehatan reproduksi pada remaja ini BKKBN mendirikan program Pusat Informasi dan Konseling Kesehatan Reproduksi Remaja (PIK-KRR) dengan tujuan untuk meningkatkan kesadaran remaja baik pria maupun wanita terhadap kesehatan reproduksinya. Tujuan 
dilakukannya penelitian ini untuk mengetahui gambaran pengetahuan remaja mengenai kesehatan reproduksi di SMA Negeri Jatinangor.

Metode Penelitian: Metode dalam penelitian ini adalah deskriptif dengan Teknik pengambilan sampel menggunakan Stratified dan Purposive Sampling dengan besar sampel sebanyak 88 responden siswa/i di SMA Negeri Jatinangor dan analisis data menggunakan distribusi frekuensi untuk mengukur pengetahuan remaja.

Hasil: Jenis kelamin responden yang mengikuti penelitian ini jumlahnya sama banyak, dengan mayoritas responden remaja akhir yang berusia 16-19 tahun sebanyak 58 responden (65,9\%). Pendidikan terakhir ayah responden mayoritas SMA/K sebanyak 25 responden $(28,4 \%)$, sedangkan untuk pendidikan terakhir ibu responden SMA/SMK 39 responden (44,3\%). Pekerjaan ayah responden mayoritas sebagai wiraswasta 31 responden $(35,2 \%)$ Sedangkan, pekerjaan ibu mayoritas adalah Tidak bekerja/IRT 61 responden $(69,3 \%)$. Seluruh responden (100\%) tidak mengikuti Program PIK-KRR, mayoritas mendapatkan sumber informasi melalui teman sebayanya sebanyak 35 responden $(39,7 \%)$. Pada tingkat pengetahuan diperoleh hasil tingkat pengetahuan siswa laki-laki mayoritas berpengetahuan cukup sebanyak 31 responden $(68,9 \%)$ sedangkan pada siswi perempuan mayoritas berpengetahuan cukup sebanyak $23(52,3 \%)$ responden.

Kesimpulan: Tingkat pengetahuan remaja di SMA Negeri Jatinangor mengenai kesehatan reproduksi mayoritas adalah siswa/i yang berpengetahuan cukup.

Kata Kunci: Pengetahuan, Remaja, Kesehatan Reproduksi

\section{PENDAHULUAN}

Remaja adalah suatu masa transisi dari masa anak-anak menjadi pribadi yang lebih dewasa, dimulai dari perubahan fisik, dan psikologis. Dan saat ini remaja tidak bisa terlepas dari masalah kesehatan reproduksi, masalah kesehatan reproduksi menjadi sangat penting bagi remaja khususnya bagi remaja wanita karena wanita akan melewati 5 siklus kehidupan dimulai dari konsepsi hingga menopause, hal ini akan melibatkan seluruh organ reproduksi sehingga sangat penting bagi wanita untuk menjaga organ reproduksi agar tetap sehat untuk mempersiapkan diri melaksanakan fungsi reproduksi yang sehat1 (Widi, R. (2011).

Berdasarkan hasil Survey Demografi Kesehatan Indonesia (SDKI) pada tahun 2015 menyatakan bahwa $57,5 \%$ pria melakukan hubungan seks pranikah karena rasa penasaran/ingin tahu yang kuat, sedangkan 38\% wanita melakukan seks karena terjadi begitu saja, sedangkan 12,6\% wanita melakukan hubungan seksual karena dipaksa oleh pasangannya. (BKKBN 2015). Dampak dari kasus tersebut banyak remaja yang mengalami masalah pada kesehatan reproduksi, salah satunya adalah HIVAIDS.
Hasil laporan situasi perkembangan HIVAIDS \& PIMS di Indonesia pada tahun 2016, sebanyak 972 remaja kelompok usia 15-19 tahun yang tercatat memiliki penyakit HIV-AIDS. (Depkes RI 2016) Menurut hasil survey yang dilakukan oleh PKBI di Jawa Barat pada tahun 2014, 93\% remaja khususnya di kota bandung melakukan seks pranikah, dan sampai saat ini tidak jarang remaja yang mengakses pelayanan kesehatan reproduksi untuk melakukan aborsi, mengobati IMS, dan HIVAIDS4. Untuk Kecamatan Jatinangor di dalam penelitian yang dilakukan oleh Wanti Mutiara didapatkan hasil dari 100 responden yang terdiri dari mahasiswa/mahasiswi di salah satu Universitas di Kecamatan Jatinangor terdapat $38 \%$ yang telah melakukan seks pranikah dengan pasangannya (Mutiara, W. (2009))

Permasalahan ini pun menjadi sorotan khusus bagi pemerintah, berbagai upaya telah dilakukan oleh pemerintah untuk menanggulagi kasus tersebut. Salah satu program yang tertulis pada kebijakan yang dibentuk oleh BKKBN adalah Pusat Informasi dan Konseling Kesehatan Reproduksi Remaja (PIK-KRR) program ini dibentuk dari, oleh, dan untuk remaja untuk memberikan pelayanan informasi dan konseling berupa persiapan kehidupan berkeluarga, TRIAD KRR (Seksualitas, HIV-AIDS, serta NAPZA) 
BKKBN mendirikan program tersebut dengan tujuan bahwa remaja baik pria maupun wanita sadar dengan pentingnya menjaga kesehatan reproduksi, dan akan lebih memperhatikan kesehatan reproduksinya.

Didalam RJPM 2015-2019 Program Informasi dan Konseling Kesehatan Reproduksi Remaja (PIKKRR) menjadi salah satu sasaran yang harus dicapai pada tahun 20197.Tetapi, berdasarkan survey SDKI 2015 sampai saat ini masih banyak remaja yang belum mengetahui dan menjalankan program tersebut, Salah satunya di Jawa Barat hanya $8,8 \%$ remaja wanita dan $4,2 \%$ remaja pria yang sudah mengetahui adanya Program PIK-KRR tersebut, salah satu faktor yang memengaruhi adalah kurangnya sosialisasi mengenai program ini, sehingga sebagian besar informasi yang remaja terima di Indonesia tentang kesehatan reproduksi adalah $53,2 \%$ dari teman sebayanya dan $38,3 \%$ dari tenaga kesehatan

\section{METODE PENELITIAN}

Jenis penelitian yang dilakukan adalah penelitian dengan menggunakan pendekatan Cross Sectional. Teknik pengambilan sampel yang dilakukan pada penelitian ini adalah Stratified dan purposive sampling yaitu sample ditentukan secara berstrata dan setelah ditentukan secara berstrata, selanjutnya sample diambil melalui suatu pertimbangan tertentu yang tentukan oleh orang yang telah mengenal populasi.
Data yang diperoleh merupakan data primer yang didapatkan langsung dari responden dengan pengisian kuesioner. Karakteristik responden yang ditetili pada penelitian ini adalah usia, jenis kelamin, pendidikan terakhir orang tua dan pekerjaan orang tua. Responden sebelumnya diberikan penjelasan terlebih dahulu oleh peneliti mengenai penelitian yang akan dilakukan serta rangkaian kegiatannya. Setelah responden menyetujui lembar persetujuan, responden diminta mengisi kuesioner yang meliputi; TRIAD KRR (Seksualitas, HIV-AIDS, NAPZA)

\section{HASIL PENELITIAN}

Berdasarkan tabel 1 diketahui bahwa jenis kelamin responden yang mengikuti penelitian ini jumlahnya sama banyak, dengan mayoritas responden remaja akhir yang berusia 16-19 tahun pada kelas XI dan XII sebanyak 58 responden $(65,9 \%)$. Pendidikan terakhir ayah responden yang mengikuti penelitian ini adalah mayoritas SMA/K sebanyak 25 responden $(28,4 \%)$, sedangkan untuk pendidikan terakhir ibu responden diketahui ibu yang berpendidikan terkahir SMA/SMK 39 responden (44,3\%). Pekerjaan orang tua responden, diketahui bahwa pekerjaan ayah responden yaitu mayoritas sebagai wiraswasta 31 responden $(35,2 \%)$. Sedangkan, untuk pekerjaan ibu diketahui bahwa mayoritas adalah Tidak bekerja/IRT sebanyak 61 responden $(69,3 \%)$.

\section{Tabel 1 Distribusi Frekuensi Berdasarkan Karakteristik}

\begin{tabular}{lcc}
\hline \multicolumn{1}{c}{ Karakteristik Responden } & Jumlah $(\mathrm{n})$ & Persentasi \\
\hline Jenis Kelamin & & \\
Laki-Laki & 44 & 50 \\
Perempuan & 44 & 50 \\
\hline Usia & & \\
Remaja Tengah & & 34,1 \\
(13-15 Tahun) & 30 & \\
Remaja Akhir & & 65,9 \\
(16-19 Tahun) & 58 & \\
\hline Pendidikan Orang tua & & \\
Ayah & & 22,7 \\
SD & 20 & 26,1 \\
SMP & 23 & 28,4 \\
SMA/SMK & 25 & \\
\hline
\end{tabular}




\begin{tabular}{lcc}
\hline D3 & 3 & \\
S1 & 14 & 3,4 \\
S2 & 3 & 15,9 \\
\hline Ibu & & 3,4 \\
SD & 14 & 15,9 \\
SMP & 25 & 28,4 \\
SMA/K & 39 & 44,3 \\
D3 & 3 & 3,4 \\
S1 & 5 & 5,7 \\
S2 & 2 & 2,3 \\
\hline Pekerjaan Orang tua & & \\
Ayah & & \\
Buruh & 13 & 14,8 \\
Guru & 2 & 2,3 \\
Karyawan Swasta & 15 & 17,0 \\
Petani & 3 & 3,4 \\
PNS & 9 & 10,2 \\
POLRI & 2 & 2,3 \\
TNI-AD & 1 & 1,1 \\
Wiraswasta & 31 & 35,2 \\
Pensiunan & 2 & 2,3 \\
Lainnya & 10 & 11,4 \\
\hline Ibu & & \\
Bidan & 1 & 1,1 \\
Buruh & 2 & 2,3 \\
Guru & 2 & 2,3 \\
Tidak Bekerja & 61 & 69,3 \\
Karyawan Swasta & 5,7 \\
PNS & 5 & 4,5 \\
Wiraswasta & 12 & 100,0 \\
Lainnya & & \\
\hline Total & & \\
\hline & & \\
\hline
\end{tabular}

Tabel 2 Distribusi Frekuensi Responden Berdasarkan Keikutsertaan siswa/i terhadap program PIK-KRR

\begin{tabular}{|c|c|c|}
\hline Keikutsertaan Siswa/i pada Program PIK-KRR & $\mathrm{N}$ & $\%$ \\
\hline Tidak & 88 & 100 \\
\hline Total & 88 & 100,0 \\
\hline
\end{tabular}

Berdasarkan tabel 2 diperoleh data bahwa seluruh responden yang berpartisipasi dalam penelitian ini tidak mengetahui adanya program PIK-KRR

Berdasarkan tabel 3 dibawah diperoleh data bahwa mayoritas responden sebanyak 35 responden $(39,7 \%)$ mendapatkan informasi dari teman sebayanya.
Berdasarkan tabel 4 dibawah diperoleh data bahwa, tingkat pengetahuan laki-laki yang di kategorikan memiliki tingkat pengetahuan yang baik sebanyak 13 responden (28,9\%), dan berpengetahuan cukup mengenai kesehatan reproduksi sebanyak 31 responden $(68,9 \%)$. Sedangkan, tingkat pengetahuan pada perempuan adalah 21 responden $(47,7 \%)$ memiliki tingkat pengetahuan yang baik, dan tingkat pengetahuan cukup sebanyak 23 responden (52,3\%). 


\section{Tabel 3 Distribusi Frekuensi Responden Berdasarkan Sumber Informasi yang di dapatkan oleh siswa/siswi}

\begin{tabular}{lcc}
\hline \multicolumn{1}{c}{ Sumber Informasi } & $\mathrm{N}$ & $\%$ \\
\hline Teman Sebaya & 35 & 39,7 \\
Media Massa/Cetak & 23 & 26,1 \\
Orang Tua & 23 & 26,1 \\
Tenaga Kesehatan & 7 & 8,1 \\
\hline \multicolumn{1}{c}{ Jumlah } & 88 & 100 \\
\hline
\end{tabular}

Tabel 4 Distribusi Frekuensi Responden Tingkat Pengetahuan Berdasarkan Jenis Kelamin

\begin{tabular}{ccccc}
\hline \multirow{2}{*}{ Tingkat Pengetahuan } & \multicolumn{2}{c}{ Laki-Laki } & \multicolumn{2}{c}{ Perempuan } \\
\cline { 2 - 5 } & $\mathrm{n}$ & $\%$ & $\mathrm{n}$ & $\%$ \\
\hline Baik & 13 & 28,9 & 21 & 47,7 \\
Cukup & 31 & 68,9 & 23 & 52,3 \\
\hline Jumlah & 88 & 100 & 88 & 100 \\
\hline
\end{tabular}

\section{PEMBAHASAN}

\section{Karakteristik Responden}

Pada hasil penelitian yang dilakukan pada Juli 2018 ini, menunjukan bahwa total responden yang berpartisipasi dalam penelitian ini antara lakilaki dan perempuan sama banyak, hal ini dikarenakan bahwa informasi mengenai kesehatan reproduksi tidak hanya perlu diketahui oleh remaja wanita, remaja laki-laki juga perlu mengetahui mengenai kesehatan reproduksinya sehingga remaja kelak dapat menentukan pilihan masa depannya (Widi ,R, 2011)

Sebagian besar responden yang mengikuti penelitian ini adalah remaja akhir yang berusia 1619 tahun sebanyak 58 responden $(65,9 \%)$. Berdasarkan pendidikan terakhir ayah responden yaitu sebagian besar adalah SMA/SMK sebanyak 24 responden $(27,0 \%)$, dan juga pendidikan terakhir ibu responden SMA/SMK 29 responden (32,6\%). Berdasarkan pekerjaan ayah responden mayoritas sebagai wiraswasta sebanyak 33 responden $(37,5)$ dan ibu sebagai Ibu Rumah Tangga sebanyak 64 responden $(72,7 \%)$.

\section{Keikutsertaan Siswa/i terhadap Program PIK- KKRR}

Pada hasil penelitian di SMA Negeri Jatinangor tidak ada siswa/i yang mengikuti Program PIK-KKR. Hal ini sesuai dengan survei yang dilakukan oleh SDKI pada tahun 2015 bahwa masih banyak remaja yang belum mengetahui adanya program PIK-KRR, faktor penyebabnya adalah kurangnya sosialisasi mengenai program ini, sehingga sumber informasi yang diterima oleh remaja mengenai kesehatan reproduksi adalah teman sebaya dan guru (PKBI 2015)

Program PIK-KRR di SMA Negeri Jatinangor ini disosialisasikan pada tahun 2012 oleh pihak Puskesmas Jatinangor dan sekarang program ini sudah tidak lagi disosialisakan di SMA Negeri Jatinangor karena tenaga kesehatan kurang aktif dalam mensosialisasikan program ini, sehingga semua siswa/i di SMA Negeri Jatinangor tidak mengikuti program PIK-KRR dan bahkan tidak mengetahui adanya program tersebut di sekolah mereka.

\section{Sumber Informasi}

Responden yang berpartisipasi dalam penelitian ini mayoritas mengetahui sumber informasi dari teman sebayanya sebanyak 35 responden $(39,7 \%)$. Hal ini sesuai dengan pernyataan Pusat Data dan Informasi Kemenkes RI pada tahun 2013 bahwa remaja baik laki-laki maupun perempuan lebih banyak berdiskusi mengenai kesehatan reproduksinya dengan teman sebaya dan gurunya (InfoDatin 2014) 


\section{Tingkat Pengetahuan Berdasarkan Jenis Kelamin Responden}

Berdasarkan hasil penelitian yang dilakukan di SMA Negeri Jatinangor, sebanyak 31 remaja lakilaki memiliki pengetahuan yang cukup mengenai kesehatan reproduksi, sedangkan untuk remaja wanita 23 responden (52,3\%) berpengetahuan cukup mengenai kesehatan reproduksi. Menurut Mubarak, pengetahuan adalah segala sesuatu yang telah diketahui berdasarkan pengalaman hidup seseorang yang telah ia dapatkan pengetahuan seseorang dapat berkembang karena rasa keingintahuan manusia yang tinggi (Mubarak, I.W. (2012)

Dalam penelitian ini, mayoritas responden memiliki pengetahuan yang cukup mengenai kesehatan reproduksi karena remaja sudah mampu untuk mencari informasi melalui media massa. Internet sebagai alat komunikasi yang paling berkembang, banyak menyediakan informasi yang dibutuhkan dan dapat di akses kapan saja dan juga dimana saja. Sehingga internet juga diketahui sebagai faktor yang memengaruhi tingkat pengetahuan seorang individu. Menurut penelitian yang dilakukan oleh Galang pada tahun 2017 dengan judul pengaruh pendidikan kesehatan terhadap tingkat pengetahuan kesehatan reproduksi remaja pada siswi kelas VIII di SMPN 28 Semarang, diketahui bahwa remaja usia akhir sudah mampu untuk menerima informasi dengan baik sehingga dapat memengaruhi tingkat pengetahuan yang dimilikinya (Galang, Pungky. (2017).tetapi dengan adanya media-media yang menyediakan berbagai macam informasi, remaja belum sepenuhnya mengerti dan mendapatkan informasi secara akurat mengenai kesehatan reproduksi ${ }^{3}$ (PKBI2015)

\section{KESIMPULAN}

Karakteristik remaja di SMA Negeri Jatinangor yang mengikuti penelitian ini terdiri dari $50 \%$ remaja pria dan $50 \%$ remaja wanita dengan mayoritas responden adalah remaja akhir yang berusia 16-19 tahun 65,9\%. Sebagian besar pendidikan terakhir ayah dan ibu responden adalah SMA/K $27,3 \%$ dan 31,8\%. Selain itu, 15,9\% pekerjaan ayah responden adalah karyawan swasta, sedangkan pekerjaan ibu adalah $72,7 \%$ sebagai ibu rumah tangga.Seluruh remaja tidak mengikuti program PIK-KRR di SMA Negeri JatinangorTerdapat $\quad 39,7 \%$ remaja yang memperoleh informasi mengenai kesehatan reproduksi dari teman sebaya. Terdapat $68,9 \%$ remaja pria memiliki pengetahuan cukup mengenai kesehatan reproduksi dan $52,3 \%$ pada remaja wanita.

\section{SARAN}

Diharapkan untuk Pengurus akademik maupun non-akademik di SMA Negeri Jatinangor mampu menjalankan kembali program PIK-KRR sebagai wadah bagi remaja untuk mendapatkan informasi dan konseling mengenai kesehatan reproduksinya. Diharapkan untuk tenaga kesehatan untuk aktif memberikan penyuluhan di sekolah maupun komunitas remaja desa mengenai kesehatan reproduksi mengingat kesehatan reproduksi sangatlah penting bagi remaja.Diharapkan untuk BKKBN melakukan evaluasi program PIK-KRR disetiap daerah apakah program di daerah tersebut berjalan sesuai rencana atau tidak, agar masalah kesehatan reproduksi remaja dapat ditangani dengan baik melalui program tersebut

\section{DAFTAR PUSTAKA}

Badan Kependudukan dan Keluarga Berencana Nasional. Rencana Strategis BKKBN. Jakarta. 2015

BKKBN. Survei Demografi dan Kesehatan Indonesia: Kesehatan Reproduksi. Jakarta: BKKBN; 2015 [Diunduh: 06 Maret 2018]

Galang, Pungky. (2017). Pengaruh pendidikan kesehatan terhadap tingkat pengetahuan kesehatan reproduksi remaja pada siswi kelas VIII di SMPN 28 Semarang. Jawa Tengah: Semarang.

InfoDATIN. Situasi Kesehatan Reproduksi Remaja. Kemenkes Rl; 2014 [Diunduh 23 Februari 2018]

Laporan situasi perkembangan HIV-AIDS dan PIMS di Indonesia. Depkes RI: 2016. Diunduh dari: http://siha.depkes.go.id/portal/files upload/Fi nal Laporan HIV AIDS TW 1 2016.pdf 
Mubarak, I.W. (2012). Promosi Kesehatan Untuk Kebidanan. Jakarta: Salemba Medika.

Mutiara, W. (2009). Gambaran perilaku seksual dengan orientasi heteroseksual mahasiswa kost di Kecamatan Jatinangor. Sumedang: Universitas Padjajaran.

Nisa, C. (2017). Peranan Pusat Informasi danKonseling Kesehatan Reproduksi Remaja (PIK-KRR) Dalam Meningkatkan
Pengetahuan Remaja tentang Kesehatan Reproduksi di SMA Negeri 1 Percut Sei Tuan. Sumatera UtaraPKBI. Kesehatan Reproduksi Remaja di Jawa Barat. 2015 [Diunduh: 06 Maret 2018]

Widi, R. (2011). Uji Validitas dan Reabilitas dalam Penelitian Epidemiologi Kedokteran Gigi. Jember: Universitas Jember. 